\title{
RANCANG BANGUN SISTEM HIDROLIK PADA MERIAM ARTILERI PERTAHANAN UDARA (57 MM) RETROFIT
}

\author{
Gunawan Pakki ${ }^{1}$, Kusnadi $^{2}$, Ardyanto Darmanto ${ }^{3}$, Gunarko ${ }^{4}$, Aristha ${ }^{5}$ \\ Prodi Teknik Otoranpur Politeknik Angkatan Darat \\ Kesatrian Pusdik Arhanud Pussenarh, Kodiklat TNI AD, Desa Pendem Kecamatan Junrejo, \\ Kota Batu, Malang, Jawa Timur \\ Email: gunawanpakki123@yahoo.com¹, kusnadi123@yahoo.com², \\ ardyantodarmanto123@yahoo.com³, gunarko123@yahoo.com ${ }^{4}$, aristha123@yahoo.com ${ }^{5}$
}

\begin{abstract}
Abstrak
Meriam $57 \mathrm{~mm}$ Retrofit merupakan salah satu alat utama sistem persenjataan (alutsista) yang dimiliki satuan Batalyon Arhanudse untuk menghalau serangan udara. Pada pergeseran meriam dari pangkalan menuju ke medan latihan/tempur atau sebaliknya, perlu dilakukan perubahan sikap angkut pada meriam terlebih dahulu. Perubahan sikap tempur ke sikap angkut pada meriam masih menggunakan pompa manual, yaitu mengayunkan tuas pompa manual untuk mengalirkan minyak hidrolik dari tangki ke silinder bogie. Piston di dalam silinder bogie akan naik sehingga terjadilah perubahan dari sikap tempur ke sikap angkut. Penggunaan pompa manual ini kurang efektif karena selain menguras tenaga, waktu pemompaan juga relatif lama \pm 1 menit. Berdasarkan hal tersebut di atas, telah dirancang sistem hidrolik untuk perubahan sikap angkut pada meriam tersebut yang terdiri dari gear pump, hydraulic hose, katup-katup, inverter, motor listrik AC. Dengan memanfaatkan sumber listrik dari baterai meriam yang diubah dari arus DC menjadi arus AC oleh inverter sehingga menggerakkan motor listrik. Ketika motor listrik dihidupkan gear pump ikut berputar karena satu poros dengannya. Gear pump akan menghisap minyak dari tangki dan memompanya ke dalam silinder bogie melalui hydraulic hose dan katup-katup yang terpasang. Sehingga terjadilah perubahaan sikap angkut yang lebih efesien tenaga dan waktu. Dari rancang bangun ini dihasilkan waktu yang dibutuhkan untuk naiknya piston bogie depan dan belakang secara bersamaan rata-rata 21 detik, lebih efisien tenaga dan waktu dibandingkan dengan pompa maual dan penyetelan flow control yang ideal, pencekikan aliran sebesar $24,89 \%$ pada saluran bogie belakang dan sebesar $4,82 \%$ pada saluran bogie depan.
\end{abstract}

Kata kunci: Meriam, silinder bogie, gear pump, motor listrik.

\section{PENDAHULUAN}

Sejalan dengan pertimbangan pimpinan pemerintahan dan militer yang terus berupaya untuk memperkuat alat utama sistem persenjataan (Alutsista) militer yang ada dengan membeli Alutsista yang terbaru dan tercanggih, maka dituntut pula sumber daya manusia yang ahli, mahir untuk mengoperasikan Alutsista yang baru. Sedangkan Alutsista yang lama perlu dilakukan langkah-langkah repowering, modifikasi, maupun retrofitting guna meningkatkan kembali performance Alutsista yang ada.

Berdasarkan hasil survey terhadap
Alutsista satuan Artileri Pertahanan Udara, khususnya pada Meriam Arhanud $57 \mathrm{~mm}$ Retrofit, akan didapatkan data bahwa pada Meriam tersebut dalam perubahan dari sikap tempur ke sikap angkut masih menggunakan pompa hidrolik manual. Pompa hidrolik manual pada meriam tersebut ada dua yaitu pada bagian depan dan pada bagian belakang. Hal tersebut kurang efektif karena selain pengoperasian pompa tersebut membutuhkan waktu relatif lama, juga menguras tenaga. Sebaliknya dalam situasi latihan ataupun pertempuran dituntut waktu pengoperasian meriam yang cepat sekaligus faktor keselamatan tetap 
diperhatikan.

Berdasarkan fakta di atas, maka perlu adanya modifikasi pada Meriam Arhanud $57 \mathrm{~mm}$ Retrofit dengan menambah pompa hidrolik manual yang telah ada dengan pompa listrik hidrolik guna meningkatkan performance meriam tersebut. Sehingga diharapkan meriam tersebut dalam perubahan dari sikap tempur ke sikap angkut dapat dioperasikan dengan waktu yang lebih singkat sehingga kesiagaan meningkat dan faktor keselamatan juga meningkat.

\section{KAJIAN PUSTAKA}

\section{Sumber Tenaga Listrik}

Terdapat 2 buah baterai pada meriam tersebut masing-masing 12 Volt DC $150 \mathrm{AH}$, maka jumlah daya listrik maksimal yang dimiliki oleh baterai sebesar 3600 Watt. Sedangkan efisiensi Watt baterai sebesar 73,47\% [1].

\section{Inverter}

Untuk memanfaatkan sumber listrik DC dari baterai ke motor listrik AC sebagai penggerak pompa hidrolik diperlukan sebuah inverter. Inverter adalah perangkat elektronika yang dipergunakan untuk mengubah tegangan DC (Direct Current) menjadi tegangan AC (Alternating Curent). Inverter dalam proses konversi tegangan DC menjadi tegangan AC membutuhkan suatu penaik tegangan berupa step up transformer [2].

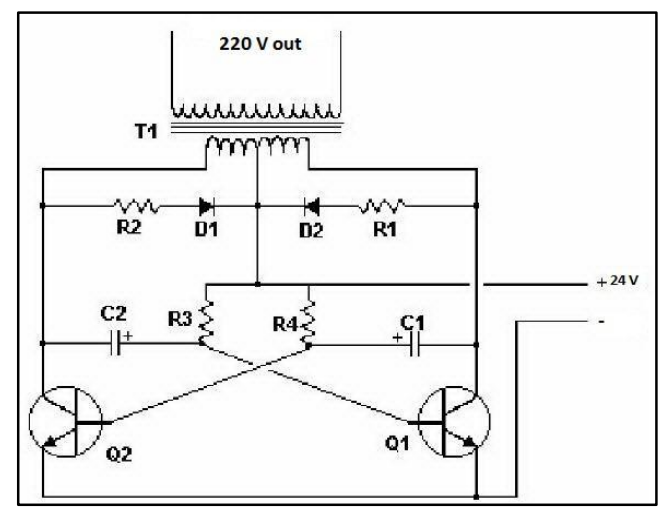

Gambar 1. Rangkaian Sederhana Inverter

Motor Listrik.

Motor listrik adalah salah satu jenis penggerak mula yang digunakan untuk mengerakkan poros pompa hidrolik. Pada dasarnya motor listrik dibedakan dari jenis sumber tegangan kerja yang digunakan. Berdasarkan sumber tegangan kerjanya motor listrik dapat dibedakan menjadi 2 jenis yaitu motor listrik arus bolak-balik AC (Alternating Current) dan motor listrik arus searah DC (Direct Current) [3].

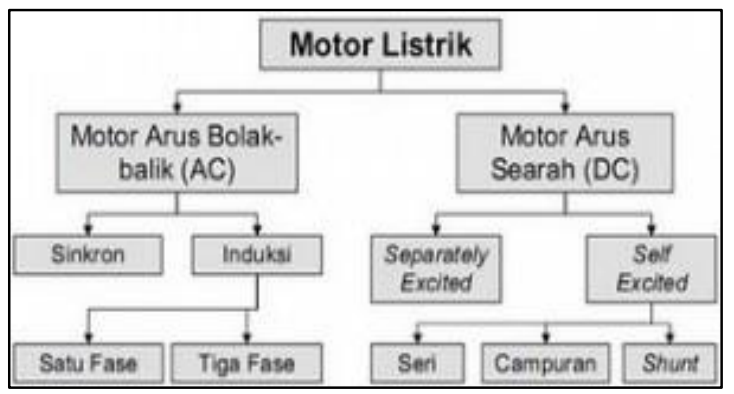

Gambar 2. Klasifikasi Motor Listrik

Pada motor satu fasa memiliki dua belitan stator, yaitu belitan fasa utama (belitan U1-U2) dan belitan fasa bantu (belitan Z1-Z2) (Gambar 3).

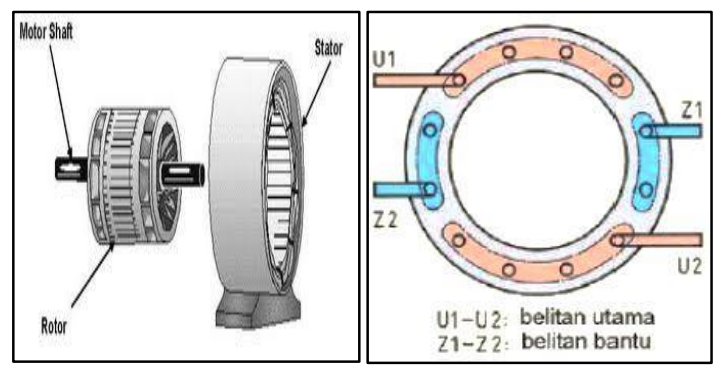

Gambar 3. Rotor dan Stator 1 Fasa

Belitan stator terdiri atas belitan utama dengan notasi terminal U1-U2, dan belitan bantu dengan notasi terminal Z1-Z2, belitan utama menggunakan penampang kawat tembaga lebih besar sehingga memiliki impedansi lebih kecil. Sedangkan belitan bantu dibuat dari tembaga berpenampang kecil dan jumlah belitannya lebih banyak, sehingga impedansinya lebih besar dibanding impedansi belitan utama. Jala-jala L1 terhubung dengan terminal U1, dan kawat netral $\mathrm{N}$ terhubung dengan terminal U2.

Kondensator berfungsi agar perbedaan sudut phasa belitan utama dengan belitan bantu mendekati $90^{\circ}$. Pengaturan arah putaran motor dapat dilakukan dengan mengubah pengawatan 
kondensator (gambar 4). Untuk menghasilkan putaran ke kiri (berlawanan jarum jam) kondensator $(\mathrm{Cb})$ disambungkan ke terminal U1 dan Z2 dan terminal Z1 dikopel dengan terminal. Sedangkan untuk menghasilkan putaran ke kanan (searah jarum jam), kondensator disambungkan ke terminal $\mathrm{Z} 1$ dan $\mathrm{U} 1$ dan terminal $\mathrm{Z} 2$ dikopel dengan terminal U1 [2].

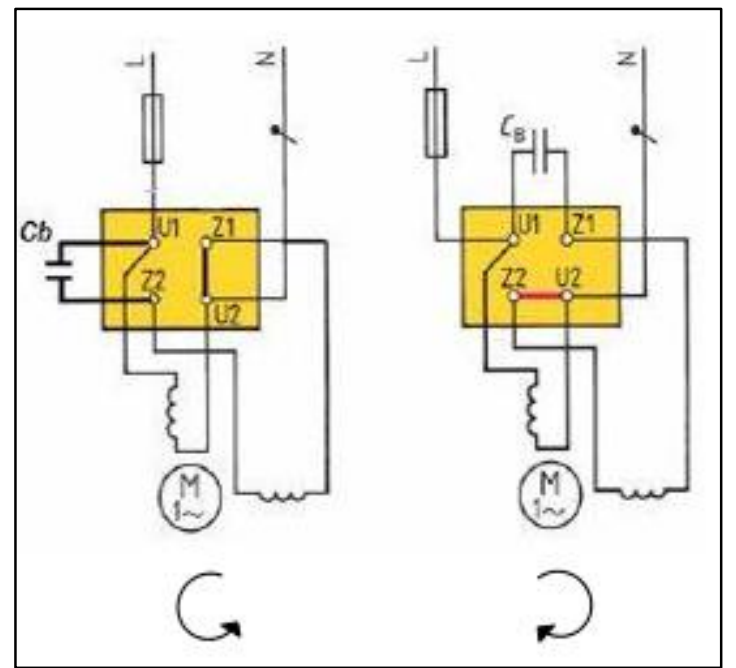

Gambar 4. Pengawatan Kondensator

\section{Sistem Hidrolik Manual}

Hidrolik adalah pemanfaatan fluida untuk memindahkan tenaga dari suatu titik ke titik yang lain. Dalam sistem hidrolik ini fluida yang digunakan adalah fluida dalam bentuk cair sama seperti yang digunakan pada sistem yang lama. Fluida pada sistem hidrolik akan meneruskan tekanan dari pompa hidrolik ke piston pada silinder hidrolik yang selanjutnya dapat mengangkat beban [5].

Mekanisme perubahan dari sikap tempur ke sikap angkut Meriam Arhanud $57 \mathrm{~mm}$ Retrofit secara manual dengan cara mengencangkan directional valve kemudian memompa minyak dengan menjungkit tuas pompa secara berulang ulang sehingga minyak hidrolik mengalir dari tangki minyak ke dalam silinder sehingga piston di dalam silinder terdorong naik ke atas dan mengubah posisi gardan meriam dari sikap tempur ke sikap angkut [6].

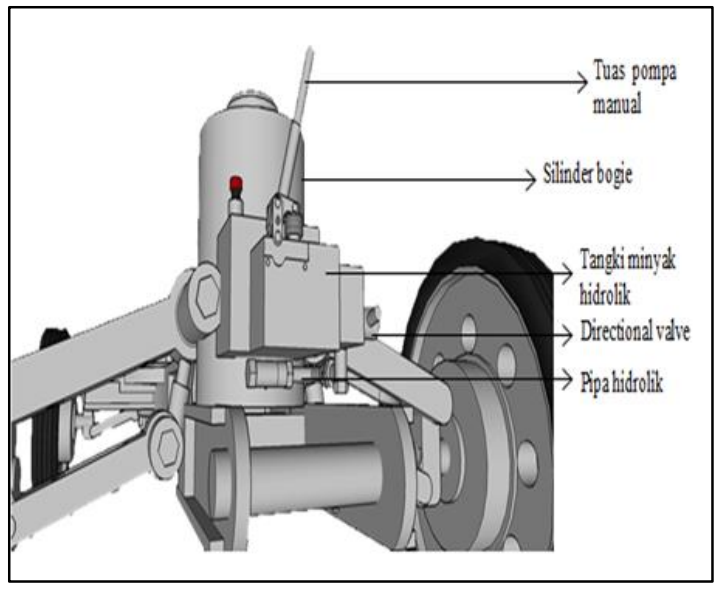

Gambar 5. Pompa Bogie Manual Meriam

\section{Penambahan Sistem Penggerak Hidrolik}

Suatu sistem hidrolik dapat bekerja dan berfungsi dengan baik apabila dilengkapi dengan lima komponen utama seperti pada gambar rangkaian sistem hidrolik sederhana sebagai berikut:

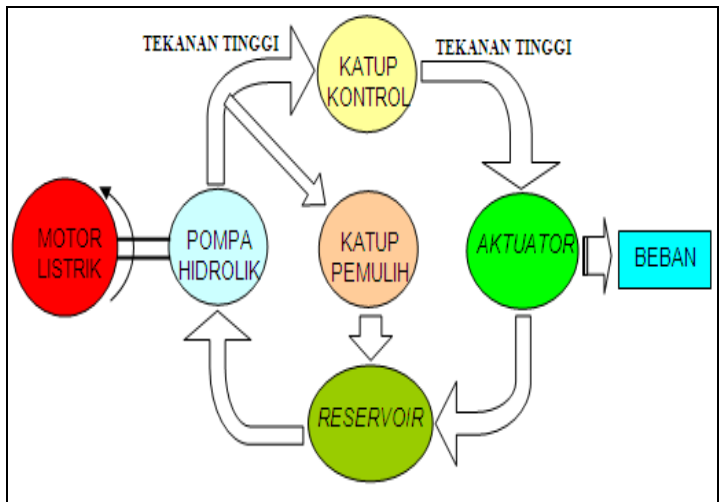

Gambar 6. Skema Hidrolik Sederhana

\section{Pompa Hidrolik}

Pompa pada sistem hidrolik berfungsi untuk menciptakan aliran fluida (memindahkan volume fluida) dan memberikan gaya yang dibutuhkan. Pompa menghisap fluida dari tangki dan mengalirkan fluida tersebut ke silinder. Faktor-faktor penting yang seharusnya ditentukan dan dipertimbangkan sebelum jenis pompa hidrolik sebenarnya dipilih adalah:

1) Tekanan maksimum yang dilayani oleh silinder, dapat diukur menggunakan pressure gauge,

2) Aliran maksimum (puncak) yang diperlukan,

3) Kemampuan pompa hidrolik beroperasi, mudah dalam 
pemeliharaannya, harga pembelian awal dan tingkat kebersihan pompa.

4) Jenisnya fixed displacement pump atau variable displacement pump.

Dalam perencanaan penambahan penggerak hidrolik ini menggunakan pompa roda gigi. Roda gigi 2 digerakkan sesuai anak panah dan menyebabkan roda gigi tiga bergerak berlawanan. Fluida dalam ruang 4 didesak keluar dan keluar dari celah roda gigi pada sisi tekan [8].

Beberapa alasan mengapa sampai saat ini pompa roda gigi masih tetap digunakan untuk menghasilkan energi hidrolik adalah sebagai berikut:

1) Konstruksinya kokoh dan sederhana,

2) Pembuatannya menguntungkan ditinjau dari segi harga,

3) Kemantapannya kerja yang tinggi dan juga pada pembebanan yang berat,

4) Tidak tergantung dari letak pemasangan,

5) Sifat penghisapan yang baik (pada putaran yang konstan),

6) Relatif tidak peka terhadap kotoran,

7) Pada penggunaannya minyak hidrolik yang normal, jangkauan viscositasnya cukup besar,

8) Jangkauan putarannya cukup besar,

9) Dapat digunakan pada berbagai daerah tekanan.

\section{Katup}

Katup adalah komponen yang utama dalam sistem hidrolik yang berfungsi untuk mengatur jumlah dan arah aliran fluida dari pompa ke silinder maupun dari silinder ke reservoir [8].

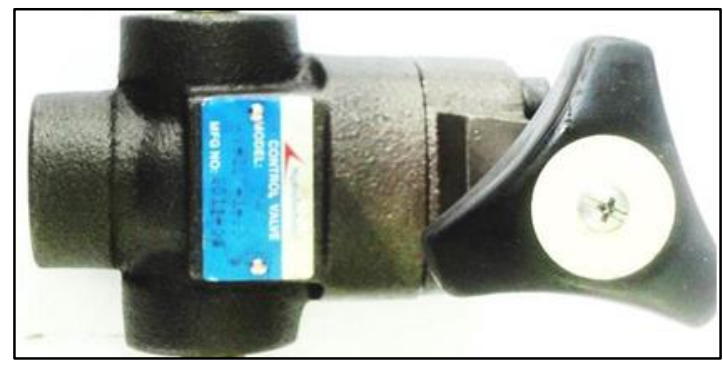

Gambar 7. Relief Valve

(Sumber : Dokumentasi)

Cara kerja katup ini, pada saat tekanan fluida yang dialirkan oleh pompa
(P) dari P1 ke P2 yang melewati katup kontrol ini melewati batas tekanan kerja dalam sistem maka fluida tersebut akan menekan pegas katup pemulih, sehingga fluida akan dialirkan kembali ke reservoir melalui saluran $\mathrm{T}$.

1) Flow Control Valve

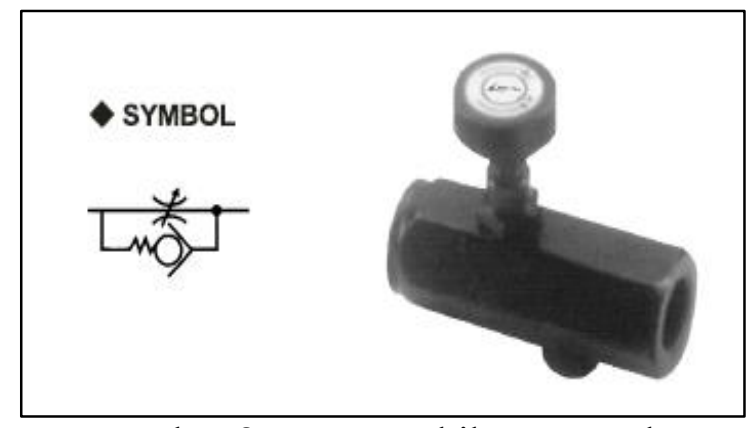

Gambar 8. Katup Cekik Satu Arah (Sumber : Dokumentasi)

Katup cekik satu arah ini digunakan untuk mengontrol debit aliran yang mengalir dari pompa hidrolik melalui saluran tekan menuju ke dalam silinder, tujuannya agar naiknya piston bogie depan dan belakang pada meriam dapat secara bersamaan.

2) Katup satu arah (one way valve)

Katup satu arah digunakan untuk memberi kesempatan aliran fluida dalam satu arah dan menutup aliran pada arah sebaliknya. Katup ini dirancang sebagai katup popet sehingga penutupan bebas kebocoran. Sebuah bola atau popet biasanya digunakan sebagai elemen penutup.

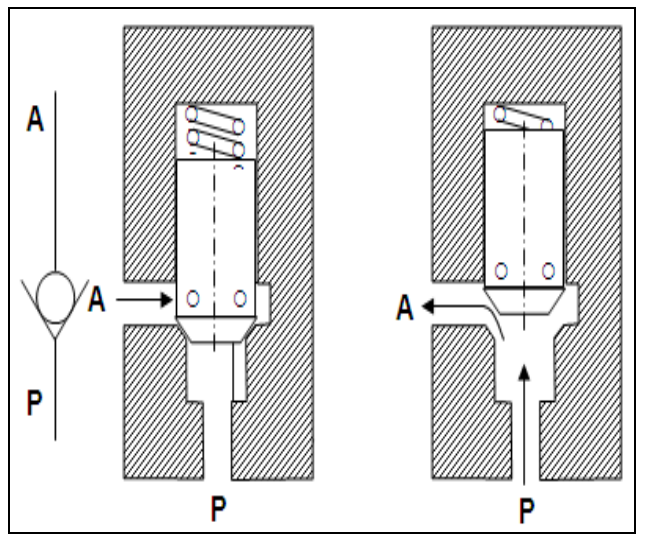

Gambar 9. Katup Satu Arah [1]

Cara kerja katup satu arah/penahan aliran balik, pada saat aliran 
fluida dari pompa (P) melalui katup searah tanda panah, popet akan terangkat dari dudukannya karena adanya tekanan fluida, maka akan mengakibatkan aliran bebas dimana fluida dari pompa (P) akan dialirkan ke saluran A. Sebaliknya apabila aliran fluida tidak melalui katup, maka pegas dan fluida balik akan mendorong popet pada dudukannya dan menutup saluran.

\section{3) Ball Valve (Kran Buka Tutup)}

Katup ini dipasang pada saluran pipa baja dan disetel tertutup pada saat menggunakan gear pump agar fluida mengalir seluruhnya kedalam silinder. Pada saat penggunaan pompa manual posisi katup ini terbuka.

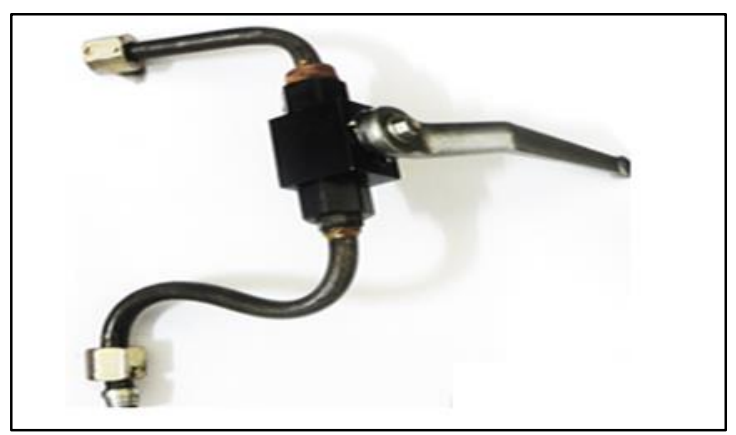

Gambar 10. Ball Valve

(Sumber : Dokumentasi)

\section{Manometer (Pressure Gauge)}

Manometer adalah salah satu komponen hidrolik yang berfungsi untuk mengetahui seberapa besar tekanan yang bekerja pada fluida. Dalam perencanaan ini menggunakan 2 buah manometer sebagai pengukur tekanan fluida.

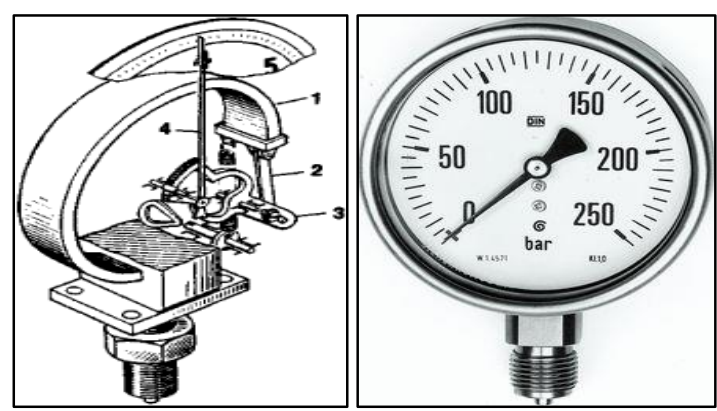

Gambar 11. Pressure Gauge

\section{Hydraulic Hose}

Pada sistem hidrolik, fluida cair dihisap dari tangki oleh pompa hidrolik disalurkan menuju ke silinder hidrolik melalui hydraulic hose. Dalam instalasi hydraulic hose harus memperhatikan halhal sebagai berikut:

1. Volume yang cukup dari hydraulic hose.

Diameter hydraulic hose harus dapat dilewati oleh aliran fluida cair secara cukup sesuai volumenya dengan panas gesekan yang minimal.

2. Panjang dan jumlah belokan hydraulic hose.

Hydraulic hose dirancang sependek mungkin terutama antara control utama dengan silinder kerja. hydraulic hose yang terlalu panjang dapat meningkatkan terjadinya friksi atau gesekan, demikian juga untuk jumlah belokan.

3. Keamanan sambungan hydraulic hose. Seluruh sambungan hydraulic hose yang menyalurkan fluida cair pada tekanan tinggi harus dikencangkan secara sempurna pada ujung sambungannya.

Hydraulic hose yang digunakan terbuat dari bahan-bahan lapisan elastomerik, fiber, dan anyaman atau tenunan kawat. Hydraulic hose secara luas banyak digunakan karena lebih mudah dalam pemasangan dan mempunyai karakteristik meredam kejutan dan getaran.

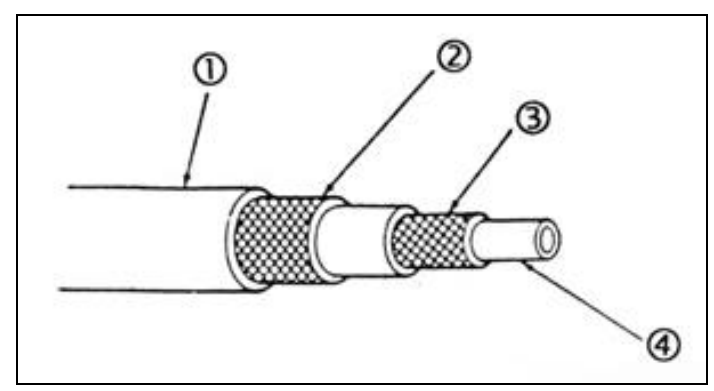

Gambar 12. Hydraulic Hose

Keterangan:

4. Lapisan pertama karet sintetis untuk melindungi,

5. Lapisan kedua jalinan kawat,

6. Lapisan ketiga/tambahan untuk tekanan yang tinggi,

7. Lapisan yang kompatibel dengan fluida.

Setelah pompa hidrolik ditentukan, maka akan dapat ditentukan jenis dan 
ukuran hydraulic hose yang diperlukan dalam perencanaan penambahan penggerak ini dengan melihat tabel pemilihan hydraulic hose.

Untuk mendukung proses perhitungan perencanaan selanjutnya maka perlu diperhitungkan hal-hal sebagai berikut:

1) Ukuran hydraulic hose

Ukuran dari hydraulic hose perencanaan dapat ditentukan dengan melihat tabel pemilihan hydraulic hose.

2) Besarnya kerugian

Sebelum dihitung berapa besarnya kerugian tinggi tekan dan tekanan yang dialami oleh fluida, maka terlebih dahulu harus diperhitungkan kecepatan aliran. Kecepatan aliran fluida didalam hydraulic hose adalah [1]:

Dimana:

$$
\mathrm{V}=\frac{\mathrm{Q}}{\mathrm{A}}
$$

$$
\begin{aligned}
& \mathrm{V}=\text { Kecepatan aliran }(\mathrm{cm} / \text { detik }) \\
& \mathrm{Q}=\text { Debit aliran }(\mathrm{cc} / \text { detik }) \\
& \mathrm{A}=\text { Luas penampang }\left(\mathrm{cm}^{2}\right)
\end{aligned}
$$

\section{METODE PENELITIAN}

\section{Perencanaan Alat}

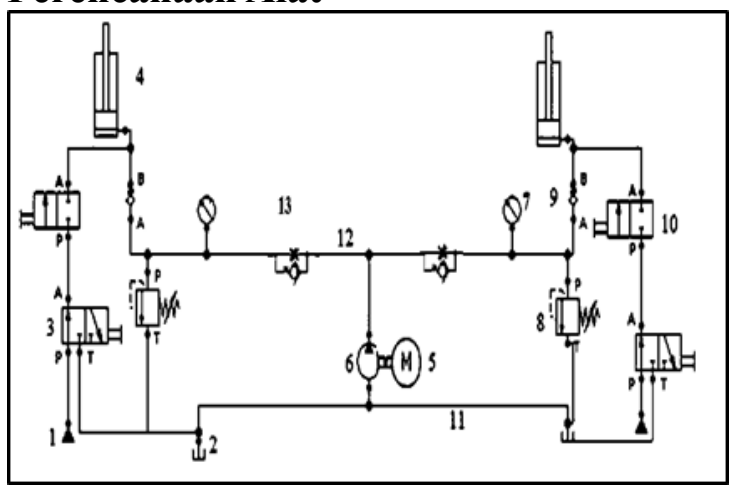

Gambar 13. Skema Hidrolik Pada Meriam

\section{Sistem Kerja Alat.}

Pada kondisi awal sebelum dilaksanakan penambahan sistem hidrolik, meriam hanya memiliki komponen seperti pompa hidrolik manual (no.1), tangki minyak hidrolik (no.2), directional valve (no.3) serta silinder bogie (no.4). Secara manual untuk melaksanakan perubahan sikap tempur ke sikap angkut, maka directional valve (katup pengarah aliran) dikencangkan sehingga arah aliran ditujukan ke silinder. Setelah itu tuas pompa manual dioperasikan sehingga minyak dari tangki minyak mengalir menuju ke dalam silinder, piston di dalam silinder akan terdorong naik ke atas sehingga terjadilah perubahan dari sikap tempur ke sikap angkut.

Sedangkan sistem kerja penambahan sistem hidrolik ini akan berfungsi pada saat sumber tenaga listrik DC dari baterai meriam diubah oleh inverter ke tegangan $\mathrm{AC}$ untuk menggerakkan motor listrik AC 2,2 kW $1400 \mathrm{rpm}$ (no.5) yang konstruksinya satu poros dengan gear pump (no.6). Pompa tersebut menghisap minyak hidrolik dari tangki minyak (no.2) melalui saluran hisap (no.11) kemudian dipompa melalui saluran tekan (no.12).

Flow Control Valve (no.13) berfungsi untuk mengatur debit aliran minyak hidrolik yang menuju ke masingmasing silinder bogie sehingga kecepatan naiknya kedua piston bogie secara bersamaan.

Tekanan dalam aliran tersebut terukur oleh manometer (no.7), besarnya tekanan yang terbaca digunakan untuk penyetingan relief valve (no.8). Katup ini berfungsi sebagai pengaman apabila terjadi tekanan yang melebihi batas yang ditentukan, maka katup ini membocorkan tekanan dan menyirkulasikan minyak hidrolik kembali menuju tangki minyak.

Namun, selama tekanannya tidak melebihi batas yang ditentukan, maka aliran minyak hidrolik akan melewati check valve (no.9) menuju ke silinder (no.4) sehingga mendorong piston dalam silinder naik ke atas, maka terjadilah perubahan sikap tempur ke sikap angkut.

Check valve berfungsi sebagai katup satu arah sehingga aliran minyak hidrolik yang sudah dipompa tidak akan kembali melalui jalur yang sama. Posisi ball valve/kran buka tutup (no.10) dalam keadaan tertutup pada saat gear pump dioperasikan agar minyak hidrolik sepenuhnya menuju ke dalam silinder. 
Sebaliknya untuk perubahan dari sikap angkut menuju ke sikap tempur sistem kerjanya hampir sama, yaitu dengan mengandalkan berat meriam tersebut. Ketika ball valve /kran buka tutup (no.10) dan directional valve/katup pengarah aliran (no.3) dibuka, maka minyak dari silinder bogie (no.4) akan terdorong kembali ke tangki minyak (no.2) sehingga piston di dalam silinder turun ke bawah dan terjadilah perubahan dari sikap angkut ke sikap tempur.

Aliran minyak hidrolik tidak akan melewati saluran tekan karena sudah terpasang check valve. Meskipun ada penambahan sistem hidrolik ini, sistem manualpun masih bisa dipergunakan seperti biasa sehingga faktor keamanan tetap terjaga pada saat sistem penambahan instalasi hidrolik ini terjadi gangguan. Sistem pompa manual bisa digunakan dengan terlebih dahulu mengencangkan directional valve dan membuka ball valve.

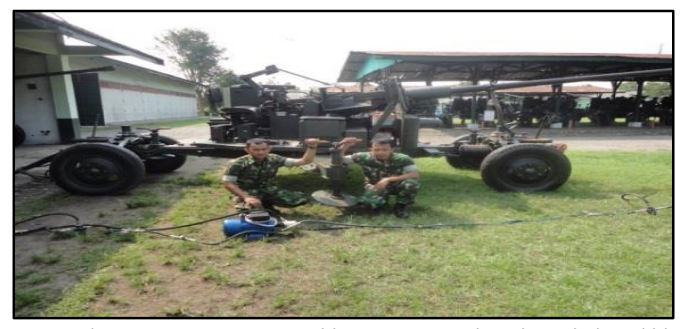

Gambar 14. Pengujian Instalasi Hidrolik

\section{HASIL PERHITUNGAN DAN PEMBAHASAN}

1. Luas silinder hidrolik

$$
=200,96 \mathrm{~cm}^{2}
$$

2. Volume silinder hidrolik

$$
\begin{aligned}
\text { V 1 sil } & =\text { A. S } \\
& =1105,28 \mathrm{~cm}^{3} \\
\text { V 2 sil } & =2.1105,28 \mathrm{~cm}^{3} \\
& =2210,56 \mathrm{~cm}^{3}
\end{aligned}
$$

3. Sumber tenaga listrik dari 2 buah baterai

$$
\begin{aligned}
\mathrm{P}_{\mathrm{a}} & =2.12 \text { Volt } .150 \mathrm{AH} \\
& =3600 \text { Watt jam }
\end{aligned}
$$

4. Out put daya baterai murni

$$
\begin{aligned}
\mathrm{P}_{\mathrm{a}}{ }^{\prime} \quad & =\eta_{\mathrm{b}} \cdot \mathrm{P}_{\mathrm{a}} \\
& =73,47 \% .3600 \text { Watt.jam } \\
& =2.645 \text { Watt.jam }
\end{aligned}
$$

Oleh karena itu jenis inverter yang dipilih untuk rancang bangun sistem hidrolik ini adalah inverter 3000 Watt, 24 Volt, 1 fasa, jenis gelombang output pure sinewave dengan efisiensi 0,85 0,95 .

5. Efisiensi Inverter

$$
\begin{aligned}
\mathrm{P}_{\mathrm{b}} & =\eta_{\text {inv. }} \mathrm{P}_{\mathrm{a}}{ }^{\prime} \\
& =85 \% .2 .645 \text { Watt.jam } \\
& =2.248 \text { Watt.jam. }
\end{aligned}
$$

Jadi pemilihan motor listriknya dengan spesifikasi 2,2 kW, $1400 \mathrm{rpm} 1$ phase 220 Volt AC karena tersedia di pasaran dan lebih terjangkau harganya.

6. Durasi pemakaian inverter $3 \mathrm{~kW}$ untuk melayani motor $2,2 \mathrm{~kW}$

$$
\mathrm{T}_{\text {inv }}=61 \text { menit }
$$

7. Perhitungan debit gear pump

$$
\mathrm{Q}=9,6 \text { liter/menit. }
$$

8. Penentuan displacement gear pump

$$
\begin{aligned}
\text { Dis } & =\frac{Q}{n} \\
& =7^{\mathrm{cc} / \mathrm{rev}}
\end{aligned}
$$

9. Waktu yang dibutuhkan untuk memompa minyak hidrolik

$$
\begin{aligned}
\mathrm{t} & =\frac{\mathrm{V}}{\mathrm{Q}} \\
& =14 \text { detik }
\end{aligned}
$$

10. Penambahan minyak hidrolik karena penambahan instalasi hydraulic hose

1) Volume saluran tekan

$$
\mathrm{V}_{\text {in }}=373 \mathrm{cc}
$$

2) Volume saluran hisap

$$
\mathrm{V}_{\text {out }}=854 \mathrm{cc}
$$

Sehingga volume penambahan minyak adalah volume saluran tekan ditambah volume saluran hisap sebesar $1.227 \mathrm{cc}$. Kecepatan aliran minyak hidrolik pada saluran tekan.

$$
\mathrm{V}=2,26 \mathrm{~m} / \mathrm{detik}
$$


Data Pengujian Dengan Flow Control Valve

Tabel 1. Data Pengujian Dengan Flow Control Valve

\begin{tabular}{|c|c|c|c|c|c|}
\hline \multirow{2}{*}{ No } & \multirow{2}{*}{ Uraian } & \multicolumn{2}{|c|}{$\begin{array}{l}\text { Pengujian } \\
\text { Tanpa Flow } \\
\text { Control }\end{array}$} & \multicolumn{2}{|c|}{$\begin{array}{c}\text { Pengujian } \\
\text { Dengan } \\
\text { Flow } \\
\text { Control }\end{array}$} \\
\hline & & 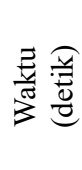 & 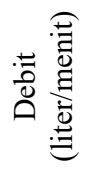 & 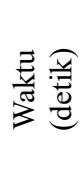 & 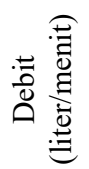 \\
\hline 1 & $\begin{array}{c}\text { Silinder } \\
\text { Bogie } \\
\text { Belakang }\end{array}$ & 14 & 4,74 & 21 & 3,16 \\
\hline 2 & $\begin{array}{l}\text { Silinder } \\
\text { Bogie } \\
\text { Depan }\end{array}$ & 20 & 3,32 & 21 & 3,16 \\
\hline
\end{tabular}

1. Selisih debit yang mengalir pada silinder belakang sebelum dan sesudah pemasangan flow control valve

$$
\begin{aligned}
\Delta \mathrm{Q} & =\mathrm{Q}_{\mathrm{Silb}}-\mathrm{Q}_{\mathrm{fc}} \\
& =4,74-3,16 \text { (liter/menit) } \\
& =1,18 \text { liter/menit }
\end{aligned}
$$

2. Persentase pencekikan flow control valve pada bogie belakang

$$
\begin{aligned}
\% \mathrm{Pc} & =\frac{\Delta \mathrm{Q}}{\mathrm{Q}_{\mathrm{Silb}}} \cdot 100 \% \\
& =\frac{1,18 \text { liter } / \text { menit }}{4,74 \text { liter } / \text { menit }} \cdot 100 \% \\
& =24,89 \%
\end{aligned}
$$

3. Selisih debit yang mengalir pada silinder depan sebelum dan sesudah pemasangan flow control valve

$$
\begin{aligned}
\Delta \mathrm{Q} & =\mathrm{Q}_{\text {Sildep }}-\mathrm{Q}_{\mathrm{fc}} \\
& =3,58-3,16 \text { (liter/menit) } \\
& =0,16 \text { liter } / \text { menit }
\end{aligned}
$$

4. Persentase pencekikan flow control valve pada bogie depan

$$
\begin{aligned}
\% \mathrm{Pc} & =\frac{\Delta \mathrm{Q}}{\mathrm{Q}_{\text {Sildep }}} \cdot 100 \% \\
& =4,82 \%
\end{aligned}
$$

\section{KESIMPULAN}

Dari hasil rancang bangun instalasi hidrolik untuk perubahan sikap angkut Meriam Arhanud $57 \mathrm{~mm}$ Retrofit didapatkan beberapa kesimpulan antara lain:
1. Waktu yang dibutuhkan untuk naiknya piston bogie depan dan belakang secara bersamaan rata-rata 21 detik,

2. Alat ini lebih efisien tenaga dan waktu dibandingkan dengan pompa maual,

3. Penyetelan flow control yang ideal, pencekikan aliran sebesar $24,89 \%$ pada saluran bogie belakang dan sebesar 4,82 $\%$ pada saluran bogie depan.

\section{REFERENSI}

[1]. Hartono, Sugi. 1988. Sistem Kontrol Dan Pesawat Tenaga Hidrolik. Edisi Pertama. Tarsito, Bandung.

[2]. Merkle, D. 1990. Festo DidacticHydraulics. Edisi Pertama. Esslingen.

[3]. Parr, Andrew. 2003. Hidrolika dan Pneumatika Pedoman Bagi Teknisi Dan Insiyur. Edisi Kedua. Erlangga. Bandung.

[4]. Bombardelli, Fabián. 2016. Experimental characterization of threedimensional flow vortical structures in submerged hydraulic jumps, Journal of Hydro-environment Research.

[5]. Yukie Tanino, 2008,Journal of Hydraulic Engineering, vol. 134, no 1, 135(8), 690-693.

[6]. Nepf, H. M. and Vivoni, E. R. (1999). "Turbulence structure in depthlimited, vegetated flow : transition between emergent and submerged regimes." Conference Proceedings of the 28th International IARH Conference, Graz, Autria.

[7]. Gimenez-Curto, L. A. and Corniero Lera, M. A. (1996). "Oscillating turbulent flow over very rough surfaces." $J$. Geophys. Res., 101(C9), 
$20745-20758$.

[8]. Cheng, N. (2013). "Calculation of drag coefficient for arrays of emergent circular cylinders with pseudofluid model." Journal of Hydraulic Engineering, 139(6), 602611. 